\title{
In vitro proliferation and differentiation of hepatic oval cells and their potential capacity for intrahepatic transplantation
}

\author{
Z. $\mathrm{Li}^{1 *}$, J. Chen ${ }^{1 *}$, L. Li ${ }^{2}$, J.H. Ran ${ }^{2}$, J. Liü ${ }^{2}$, T.X. Gao ${ }^{3}$, B.Y. Guo ${ }^{3}$, X.H. Li ${ }^{1}$, Z.H. Liu ${ }^{1}$, G.J. Liu ${ }^{1}$ \\ Y.C. Gao ${ }^{1}$ and X.L. Zhang \\ ${ }^{1}$ Department of Hepatobiliary Surgery, Liaocheng People's Hospital, Liaocheng, Shandong, China \\ ${ }^{2}$ The First People's Hospital of Kunming, Kunming, Yunnan, China \\ ${ }^{3}$ Dongchangfu Hospital of Women and Child Health Care, Liaocheng, Shandong, China
}

\begin{abstract}
Hepatic oval cells (HOCs) are recognized as facultative liver progenitor cells that play a role in liver regeneration after acute liver injury. Here, we investigated the in vitro proliferation and differentiation characteristics of HOCs in order to explore their potential capacity for intrahepatic transplantation. Clusters or scattered HOCs were detected in the portal area and interlobular bile duct in the liver of rats subjected to the modified 2-acetylaminofluorene and partial hepatectomy method. Isolated HOCs were positive for c-kit and CD90 staining (99.8\% and $88.8 \%$, respectively), and negative for CD34 staining (3.6\%) as shown by immunostaining and flow cytometric analysis. In addition, HOCs could be differentiated into hepatocytes and bile duct epithelial cells after leukemia inhibitory factor deprivation. A two-cuff technique was used for orthotopic liver transplantation, and HOCs were subsequently transplanted into recipients. Biochemical indicators of liver function were assessed 4 weeks after transplantation. HOC transplantation significantly prolonged the median survival time and improved the liver function of rats receiving HOCs compared to controls $(P=0.003$, Student $t$-test). Administration of HOCs to rats also receiving liver transplantation significantly reduced acute allograft rejection compared to control liver transplant rats 3 weeks following transplantation (rejection activity index score: control $=6.3 \pm 0.9 ; \mathrm{HOC}=3.5 \pm 1.5 ; \mathrm{P}=0.005$ ). These results indicate that $\mathrm{HOCs}$ may be useful in therapeutic liver regeneration after orthotopic liver transplantation.
\end{abstract}

Key words: Hepatic oval cells; Proliferation; Differentiation; Liver transplantation

\section{Introduction}

Liver transplantation offers an efficient and efficacious approach for treating patients with end-stage liver diseases. However, liver transplantation is usually associated with considerable long-term side effects, including chronic renal failure (1), post-transplantation lymphoproliferative disorder (2), and cardiovascular complications (3). Transplantation of stem cells or progenitor cells can be utilized as alternative solutions to repair or regenerate damaged liver due to their ability to self-renew and their capability to differentiate into a variety of specialized cell types (4). Hepatocytes and hepatic oval cells (HOCs) are the potential source of endogenous stem/progenitor cells for liver regeneration and repopulation $(5,6)$. Importantly, intra-hepatic progenitor cells (HOCs) play critical roles when hepatocyte proliferation is blocked or delayed (6).
Although it has been suggested that HOCs may provide an extension of the canal of Hering (7), the precise origination of these cells is not known. These cells have a high nuclear-to-cytoplasmic ratio and express markers of immature liver cells [ $\alpha$-fetoprotein (AFP)], hepatocyte lineage (albumin), and biliary epithelium [cytokeratin 19 (CK19)] (8,9). HOCs display a distinct phenotype and have been shown to be a bipotential progenitor of two types of epithelial cells found in the liver: hepatocytes and bile ductular cells (10). Moreover, HOCs are capable of generating other cells, such as intestinal epithelium and pancreatic acinar cells $(6,11,12)$. A variety of liver injury models have been used to induce HOC proliferation, such as 2-acetylaminofluorene (2-AAF)/ partial hepatectomy $(\mathrm{PH})$-induced injury $(13,14)$, a

Correspondence: Z. Li, Department of Hepatobiliary Surgery, Liaocheng People's Hospital, No. 67 Dongchang West Road, Liaocheng 252000, Shandong, China. E-mail: IIIIIzhu@126.com

${ }^{*}$ These authors contributed equally to this study. 
3,5-diethoxycarbonyl-1,4-dihydrocollidine diet (9), choline deficiency, an ethionine-supplemented diet (15), and 2-AAF/ $/ \mathrm{CCl}_{4}$ (16) or 1,4-bis[N, N'-di(ethylene)phosphamide]-piperazine (dipin)/PH-induced injury (17). Among these models, 2-AAF combined with a two-thirds $\mathrm{PH}$ has been widely used for stimulating the proliferation of HOCs; however, significant mortality was observed after a two-thirds $\mathrm{PH}$ (18). Therefore, a more efficient approach for generating $\mathrm{HOCs}$ with low animal mortality is still needed. In addition, the potential capacity of HOCs for intrahepatic transplantation has not been fully explored.

In this study, we successfully induced the proliferation of $\mathrm{HOCs}$ in male Lewis rats using 2-AAF combined with a one-half to one-third $\mathrm{PH}$ (left lateral lobe excision) and determined the in vitro proliferation and differentiation capability of isolated HOCs. In addition, the intrahepatic transplantation ability of HOCs was evaluated. Our results provide a better understanding of the involvement of HOCs during liver repair and regeneration and suggest that HOCs may have valuable properties for therapeutic liver regeneration after orthotopic liver transplantation.

\section{Material and Methods}

\section{Reagents}

Fetal bovine serum (FBS), $0.25 \%$ trypsin, type IV collagenase, and phosphate-buffered saline (PBS) were purchased from Gibco (USA). D-Hank's solution was purchased from HyClone (USA). The 2-AAF (Cat No. 00300) and DMEM/F12 culture medium were obtained from Sigma-Aldrich (USA). Hepatocyte growth factor (HGF; Cat No. 2207-HG), epidermal growth factor (EGF; Cat No. 400-25), stem cell factor (SCF; Cat No. 400-22), and leukemia inhibitory factor (LIF; Cat No. LIF3005) were purchased from Cytolay (USA). FITC-conjugated rat antiCD34 (Cat No. SC-7324) and rabbit IgG anti-c-kit polyclonal antibodies were provided by Santa Cruz (USA). FITC-conjugated rat anti-CD90 (Cat No. 202503) antibody was provided by Biolegend (USA). FITC-labeled goat anti-rabbit IgG antibody was purchased from Beijing Zhong Shan-Golden Bridge Biological Technology Co., Ltd. (China). Specific primers for albumin (ALB), CK19, and $\beta$-actin were synthesized by Shanghai Chaoshi Biotechnologies Co. (China). The hematoxylin and eosin (H\&E) staining kit was obtained from Shanghai Sangon Biological Engineering Technology and Services Co., Ltd. (China).

\section{Animals}

Male and female specific pathogen-free (SPF) Lewis rats weighing $200 \pm 20 \mathrm{~g}$ (used for HOCs isolation) or 250-300 g (used for transplantation) were provided by Vital River Lab Animal Technology Co., Ltd. (China). Female SPF dark agouti (DA) rats weighing 200-250 g were provided by the Laboratory Animal Center of Harbin Medical University, Harbin, China. All efforts were made to minimize animal suffering and to reduce the number of animals used. All animal procedures and the study were approved by the Ethics Committee of Liaocheng People's Hospital, Liaocheng, Shandong, China.

\section{Activation of oval cell proliferation by the 2-AAF/PH model}

Male Lewis rats were housed separately for 1 week prior to use. Daily, the rats were given $20 \mathrm{mg} / \mathrm{kg}$ body weight 2-AAF dissolved in vegetable oil by intragastric administration for 6 days. On the 7th day, 10 animals were partially hepatectomized (left lateral lobe excision, onehalf to one-third $\mathrm{PH}$ ) under general ether anesthesia without 2-AAF administration, and 2-AAF feeding was continued from the 8 th to the 14th day.

\section{Histological examination}

Ten days after surgery, animals were killed and liver tissues were removed and fixed with $10 \%$ buffered formaldehyde. Paraffin-embedded sections were stained with H\&E using a standard procedure and then assessed under a phase contrast microscope (Olympus, Japan).

\section{Primary culture of HOCs}

The isolation of HOCs was performed 10 days after surgery. Briefly, liver tissue was minced, washed with D-Hank's solution, and digested with DMEM/F12 culture medium containing $0.1 \%$ collagenase IV and $0.025 \%$ EDTA at $37^{\circ} \mathrm{C}$ for $15 \mathrm{~min}$. Cells were filtered through a 100 mesh filter and centrifuged at $340 \mathrm{~g}$ for $5 \mathrm{~min}$ at $4^{\circ} \mathrm{C}$. HOCs were separated by Percoll gradient centrifugation (Amersham Biosciences, USA). The cells were then seeded onto gelatin-coated flasks and maintained in DMEM/F12 culture medium supplemented with $10 \%$ FBS, $100 \mathrm{U} / \mathrm{mL}$ penicillin, $100 \mu \mathrm{g} / \mathrm{mL}$ streptomycin, and $1 \mathrm{ng} / \mathrm{mL}$ amphotericin $\mathrm{B}$ at $37^{\circ} \mathrm{C}$ in a $5 \% \mathrm{CO}_{2}$ incubator. Three days after seeding, $20 \mathrm{ng} / \mathrm{mL}$ SCF, $10 \mathrm{ng} / \mathrm{mL}$ HGF, $10 \mathrm{ng} / \mathrm{mL}$ EGF, and $10 \mathrm{ng} / \mathrm{mL}$ LIF were added to the culture medium. Subculture was performed using $0.25 \%$ trypsin for digestion. To induce differentiation, LIF was withdrawn from the culture medium and the cells were maintained in culture. Images were captured and quantitatively analyzed with an image analysis system (APIAS1000, Shenzhen, Huahai Electronics, Co., Ltd., China).

\section{MTT assay}

To evaluate cell proliferation, the 3-(4,5-dimethylthiazol2-yl)-2,5-diphenyltetrazolium bromide (MTT) assay was performed. Cells were seeded onto 24-well plates at a density of $1 \times 10^{7}$ cells/well. At the indicated time points after cell seeding, $20 \mu \mathrm{L}$ MTT $(5 \mathrm{mg} / \mathrm{mL})$ was added to each well, and the cells were cultured for an additional $4 \mathrm{~h}$ at $37^{\circ} \mathrm{C}$. The medium was then removed, and $150 \mu \mathrm{L}$ dimethyl sulfoxide was added to each well to resuspend the MTT metabolic product. The absorbance of the dissolved formazan was measured at a wavelength of $570 \mathrm{~nm}$ with a 
scanning microplate spectrophotometer (Biotek, USA). Three replicate wells were assessed for each experimental group.

\section{Electron microscopy}

For transmission electron microscopy (TEM) analysis, HOCs or tissue samples were fixed with $2.5 \%$ glutaraldehyde for $2 \mathrm{~h}$ and then post-fixed with $1 \% \mathrm{OsO}_{4}$. After dehydration through a graded ethanol series and acetone [30\% (v/v) ethanol (15 min), 50\% (v/v) ethanol (15 min), $70 \%(\mathrm{v} / \mathrm{v})$ ethanol (15 $\mathrm{min}), 90 \%(\mathrm{v} / \mathrm{v})$ ethanol (15 min), $95 \%$ (v/v) ethanol (15 min), 50\% (v/v) acetone (10$15 \mathrm{~min}), 70 \%$ (v/v) acetone (10-15 min), 90\% (v/v) acetone (10-15 min), and three washes with $100 \%(\mathrm{v} / \mathrm{v})$ acetone $(30 \mathrm{~min})]$, the samples were embedded in Epon812. Ultrathin sections were stained with uranyl acetate and lead citrate and examined by TEM (Hitachi Science Systems, Ltd., Japan). For scanning electronic microscopy (SEM) analysis, samples were fixed with $2.5 \%$ glutaraldehyde for $12 \mathrm{~h}$. After dehydration in an acetone gradient [50\% (v/v) acetone (10-15 $\mathrm{min}), 70 \%$ $(\mathrm{v} / \mathrm{v})$ acetone (10-15 $\mathrm{min})$, and $90 \%(\mathrm{v} / \mathrm{v})$ acetone (10-15 min)], spray-dried samples were analyzed by SEM (S-3400-N, Hitachi Science Systems, Ltd.).

\section{Immunocytochemistry}

Immunocytochemical analysis was performed as previously described (19). Briefly, cells were fixed with $4 \%$ paraformaldehyde (PFA), rinsed with PBS, and immunostained with an anti-c-kit primary antibody (1:100 dilution) in a humidity chamber overnight at $4^{\circ} \mathrm{C}$. After washing three times with PBS, the cells were stained with FITClabeled goat anti-rabbit IgG secondary antibody (1:80 dilution) for $40 \mathrm{~min}$ at $37^{\circ} \mathrm{C}$. After washing with PBS, the samples were mounted with $2 \%$ glycerol, and fluorescence was detected under a fluorescence microscope (Olympus).

\section{Flow cytometry}

The cell surface markers c-kit, CD34, and CD90 were assessed by flow cytometry analysis. Fifty microliters of $1 \times 10^{6}$ cells suspended in PBS were incubated with the ckit primary antibody (1:100 dilution) for $50 \mathrm{~min}$ at room temperature. After centrifugation, the cells were washed and stained with FITC-labeled goat anti-rabbit lgG secondary antibody (1:80 dilution) for $30 \mathrm{~min}$ at room temperature. For CD34 and CD90 labeling, the same volume of cells was incubated with FITC-labeled anti-CD34 (1:100 dilution) or anti-CD90 (1:100 dilution) antibodies for $30 \mathrm{~min}$ at room temperature. After they were washed with PBS two times for $5 \mathrm{~min}$ each, the cells were analyzed using fluorescenceactivated cell sorting (FACS; BD Biosciences, USA).

\section{Quantitative real-time reverse-transcription polymerase chain reaction (qRT-PCR)}

Total RNA was extracted from HOCs, differentiated HOCs, liver tissues, or bile duct tissues using the Trizol reagent (Sigma-Aldrich). After purification, the integrity of the purified mRNA was confirmed by agarose gel electrophoresis. The cDNA was then transcribed with the first cDNA synthesis kit according to the manufacturer's instructions (Fermentas, USA). The sequences of the specific primers used are as follows: ALB: forward: 5'-TGTCACGGCGACCTGTTG-3', reverse: 5'-GG AGATAGTGGCCTGGTTCTCA-3'; CK19: forward: 5'-GA CTTCCGGACCAAGTTTGAG-3', reverse: 5'-CGC AGGCCGTTGATGTC-3'; $\beta$-actin: forward: $5^{\prime}$-ACCG AGCGCGGCTACAGC-3', reverse: 5'-CTCATTGCCAA TGGTGAT-3'. PCR amplification was carried out on a real-time fluorescence quantitative instrument (Roche Diagnostics, Switzerland). The primer concentration was $20 \mathrm{pM}$ and PCR efficiency of the kit was $96.3 \%$. The thermocycling conditions were as follows: $60^{\circ} \mathrm{C}$ for $2 \mathrm{~min}$, $94^{\circ} \mathrm{C}$ for $10 \mathrm{~min}$, and then 40 cycles at $94^{\circ} \mathrm{C}$ for $15 \mathrm{~s}$ and $60^{\circ} \mathrm{C}$ for $60 \mathrm{~s}$. The amplified products were analyzed with real-time fluorescence quantitative instrument software. Fold changes in target gene expression were then normalized with the following formula: fold change $=2^{-\Delta(\Delta \mathrm{Ct})}$. The negative log was calculated and data were analyzed from 20 independent experiments.

\section{Cell transplantation}

The two-cuff (portal vein and infrahepatic vena cava) technique was used to establish orthotopic liver transplantation in rats as previously described $(20,21)$. Female DA rats were used as donors and female Lewis rats served as recipients. The recipients were randomly divided into two groups: the control group $(n=60)$ and the cell transplantation group $(n=60)$. In the control group, animals received orthotopic liver transplantation, and in the cell transplantation group, $1 \mathrm{~mL}$ of $1 \times 10^{6}$ cells/ $\mathrm{mL}$ HOCs (passage 4-10) was injected into the portal vein and hepatic artery in animals receiving the liver transplantation. Recipients were given tacrolimus starting on the day prior to surgery until the 13th day post-surgery. Liver function indicators, including alanine aminotransferase (ALT), direct bilirubin (DBil), ALB, $\gamma$-glutamyltransferase (GGT), alkaline phosphate (ALP), and cholinesterase (ChE) were examined 4 weeks after transplantation using a Beckman CX9 automatic biochemical analyzer (Beckman Coulter, Germany).

\section{Evaluation of liver allograft rejection}

Three weeks after transplantation, tissue sections were stained with $\mathrm{H} \& \mathrm{E}$, samples were mounted, and fluorescence detected using a fluorescence microscope (Olympus). The severity of acute rejection was assessed using the rejection activity index (RAI) according to the Banff classification of hepatic allograft rejection (22).

\section{Statistical analysis}

Data were analyzed by the SPSS 16.0 software (SPSS, Inc., USA) and are reported as means \pm SD. 

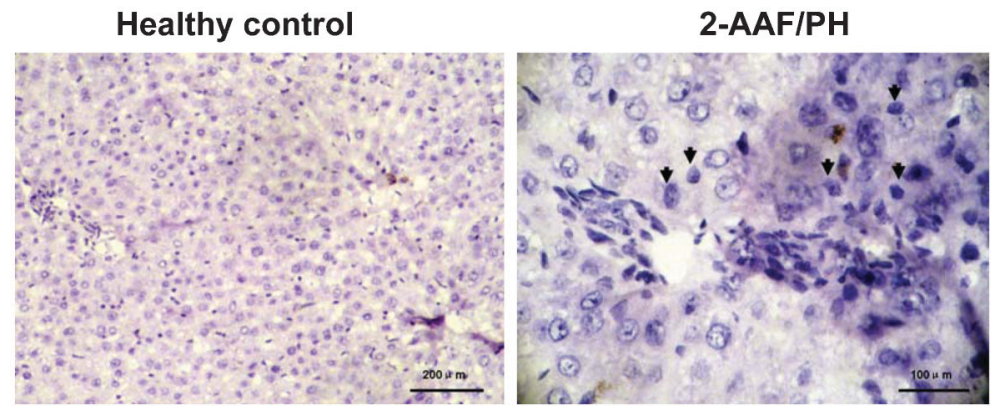

Figure 1. Hematoxylin \& eosin staining of liver tissues. Liver tissues were obtained from healthy rats or rats that received 2-acetylaminofluorene (2-AAF)/partial hepatectomy (PH) for 8 days. Proliferating hepatic oval cells (HOCs) are indicated by arrows.
Comparisons between different groups were carried out using one-way analysis of variance. Comparisons within one group were achieved using the Student $t$-test. $\mathrm{P}<0.05$ was considered to be statistically significant.

\section{Results}

\section{Establishment of an HOC proliferation model}

In order to establish the HOC proliferation model, 10 Lewis rats received $2-A A F$ in combination with a left lateral lobe excision, and six rats survived for 10 days post-surgery. Two rats died as a result of the surgery, and two others died of postoperative abdominal infection or frequent diarrhea. Gross examination on the 10th day post-operation showed that the livers were enlarged and had obvious signs of congestion. H\&E staining of the liver sections showed a disintegrated hepatic lobule and irregularly arranged hepatic plate. Clusters or scattered HOCs were detected in the portal area and interlobular bile duct (Figure 1). In addition, the diameters of HOCs varied with a range of $7-19 \mu \mathrm{M}$, and the cytoplasm of these cells contained dark, basophilic material.

\section{Identification of isolated HOCs}

HOCs were isolated from liver tissues of rats that had received $2-\mathrm{AAF} / \mathrm{PH}$. The cell viability was approximately
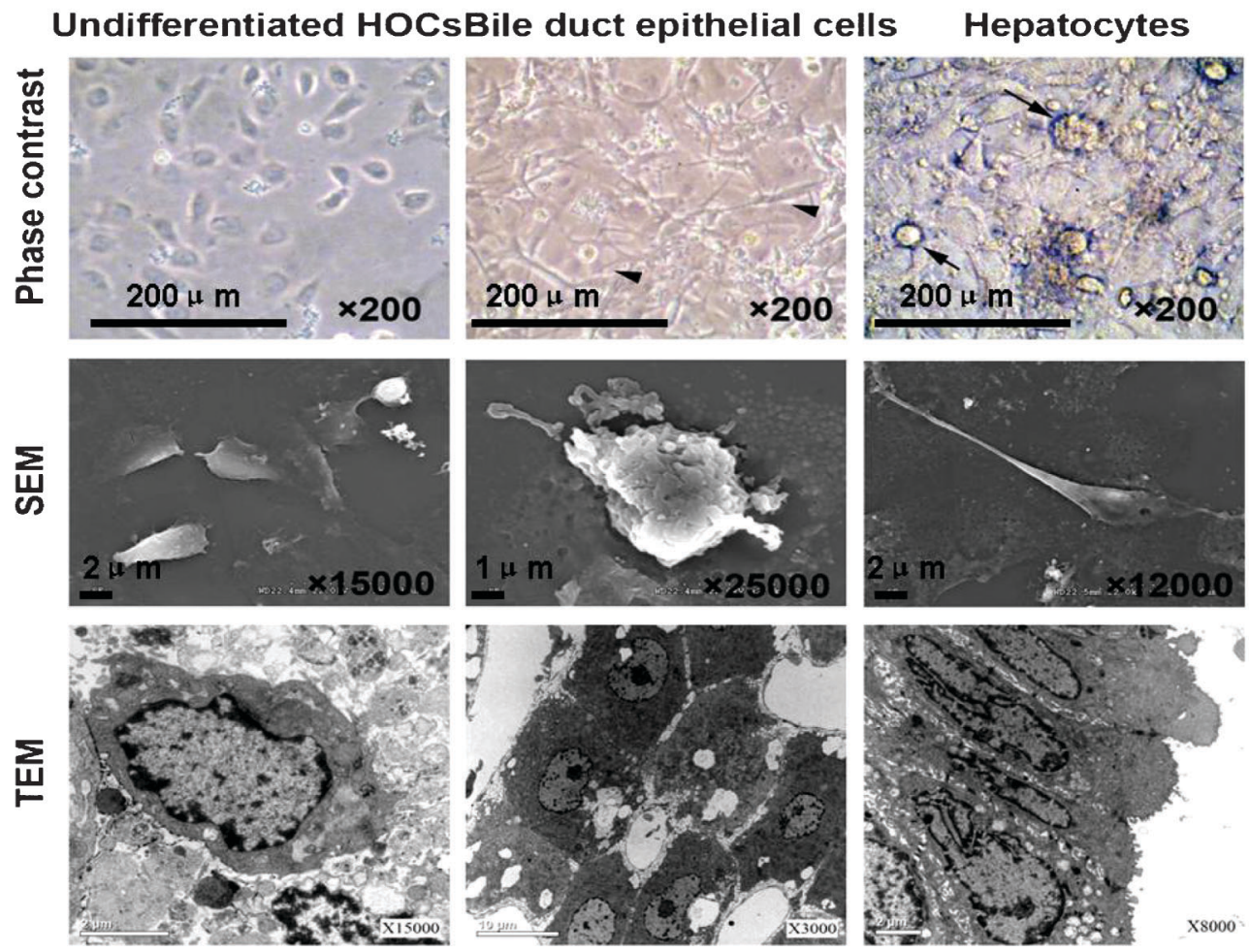

Figure 2. Differentiation capabilities of hepatic oval cells (HOCs). Leukemia inhibitory factor (LIF) was withdrawn from the culture medium to induce cell differentiation for 3 days. Passage-4 HOCs were used for differentiation. Undifferentiated or differentiated cells were monitored by phase contrast microscopy, scanning electronic microscopy (SEM), or transmission electron microscopy (TEM). Arrowhead: a long spindle-like bile duct epithelial cell; arrow: a large round-shaped hepatocyte. 


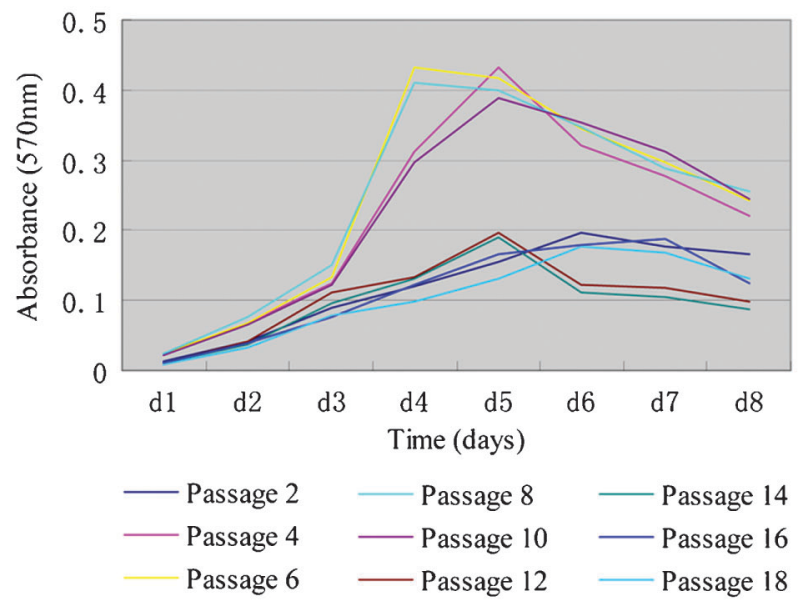

Figure 3. Growth curves of hepatic oval cells (HOCs) collected from different passages. The viability of HOCs from passage 2-18 was determined by 3-(4,5-dimethylthiazol-2-yl)-2,5-diphenyltetrazolium bromide (MTT). Data are reported as means \pm SD.

95\% based on trypan blue dye exclusion (data not shown). After adhesion, round, oval, or short spindle-like cells multiplied rapidly in culture medium supplemented with SCF, HGF, EGF, and LIF (see Figure 2). MTT analysis revealed that passage 4-10 HOCs multiplied very fast compared to other passages (Figure 3), and therefore these HOCs were used for transplantation. Moreover, the HOCs were immunopositive for c-kit (Figure 4A), and flow cytometry analysis revealed that HOCs of passage 4 were 99.8\% and $88.8 \%$ immunopositive for c-kit and CD90, respectively, but immunonegative for CD34 (3.6\%; Figure 4B-D). These results provided evidence that the isolated cells were HOCs.

\section{In vitro differentiation capability of HOCs}

To induce HOC differentiation, LIF was withdrawn from the culture medium. HOCs were differentiated into large, round-shaped hepatocytes and long spindle-like bile duct epithelial cells (Figure 2). TEM analysis further demonstrated that typical HOCs presented a relatively high nucleus-to-cytoplasm ratio (Figure 2). Heterochromatin was enriched in the nucleus, and few cellular organelles were observed in the cytoplasm of HOCs. The hepatocytes derived from HOCs were regular polygon-shaped cells with enriched cellular organelles, and the bile duct epithelial cells were single cuboidal or single columnar epithelium cells with microvilli. Both undifferentiated and differentiated HOCs expressed the liver and bile duct markers ALB and CK19 as determined by qRT-PCR analysis (Figure 5 and Table 1). In addition, the mRNA level of CK19 in HOCs was significantly lower than that in differentiated HOCs. These data further confirmed that the isolated HOCs were liverderived hepatic progenitors.

\section{HOC transplantation}

HOC transplantation significantly prolonged the median survival time (MST) for recipients $(n=33)$ compared to controls ( $n=47 ; 38$ vs 21 days, respectively; $P=0.003$ ). A gross examination of the liver was performed immediately after the rats were killed. The control group exhibited liver swelling and cirrhosis accompanied with liver ischemia, congestion, and hemorrhage. In contrast, although local liver congestion was observed in animals with HOC transplantation, no cirrhosis or necrosis was detected. Moreover, HOC transplantation dramatically improved liver function in recipients 4 weeks after transplantation (Table 2). Histological examination indicated that administration of HOCs to rats also receiving liver transplantation
A

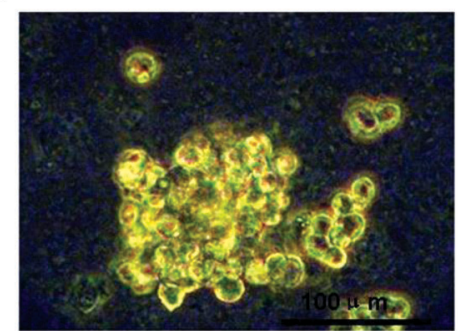

C

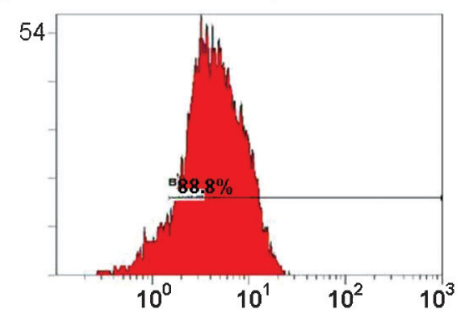

B

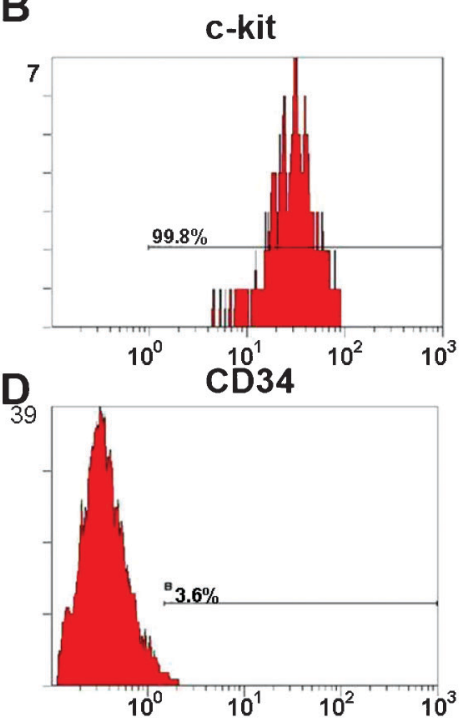

Figure 4. Identification of hepatic oval cells (HOCs). A, HOCs in suspension culture were immunostained with an anti-c-kit antibody. Positive cells appear as yellow fluorescence by fluorescence microscopy. $B-D$, The percentage of c-kit $(B), \operatorname{CD} 90(C)$, or CD34 $(D)$ positive HOCs (passage 4) was evaluated by flow cytometry analysis. $x$-axis: number of cells; $y$-axis: percent. 
Table 1. Quantification of the mRNA expression of ALB and CK19 by RT-PCR.

\begin{tabular}{llc}
\hline & ALB & CK19 \\
\hline Liver & $-1.139 \pm 0.588^{\star \#}$ & $-1.926 \pm 0.653^{\star \#}$ \\
Bile duct & $-6.138 \pm 0.521^{* \#}$ & $-1.739 \pm 0.704^{*}$ \\
Undifferentiated HOCs & $-1.820 \pm 0.614$ & $-3.852 \pm 0.974^{\#}$ \\
Differentiated HOCs & $-1.758 \pm 0.543$ & $-1.492 \pm 0.634^{*}$ \\
\hline
\end{tabular}

Data are reported as means \pm SD for 20 independent experiments and normalized with $\beta$-actin. ALB: albumin; CK19: cytokeratin 19. The negative log was calculated as described in Material and Methods. ${ }^{*} \mathrm{P}<0.05$ vs undifferentiated hepatic oval cells (HOCs); ${ }^{\#} \mathrm{P}<0.05$ vs differentiated HOCs (Student $t$-test).

presented healthy liver tissue and significantly reduced the RAI scores compared to control liver transplant rats 3 weeks following transplantation (RAl: control $=6.3 \pm 0.9$; $\mathrm{HOC}=3.5 \pm 1.5 ; \mathrm{P}=0.005$; Figure 6 ), suggesting that transplantation in the presence of HOCs decreased liver allograft rejection.

\section{Discussion}

Proliferation of differentiated hepatocytes plays an essential role during liver regeneration after injury. However, in cases where hepatocyte proliferation is impaired or delayed, HOCs will proliferate and invade the adjacent liver parenchyma, where they differentiate into hepatocytes or biliary cells (6). Although 2-AAF combined with two-thirds $\mathrm{PH}$ is currently the most widely used model for oval cell activation $(13,14)$, animal mortality rate is relatively high due to the two-thirds $\mathrm{PH}$ (18). In our preliminary experiments, we found that most of the Lewis rats receiving a two-thirds $\mathrm{PH}$ died 1-2 days following the operation, and no animals survived to the 10th day postoperation (data not shown). Therefore, the 2-AAF/PH

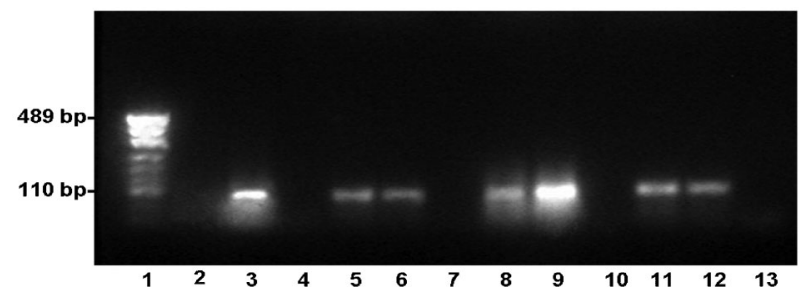

Figure 5. Expression of albumin (ALB) and cytokeratin 19 (CK19) mRNA in hepatic oval cells (HOCs) or liver and bile duct tissues as determined by quantitative real time reverse-transcriptase polymerase chain reaction. Lane 1: DNA marker; lane 2: ALB in bile duct; lane 3: CK19 in bile duct; lane 4: empty control; lane 5: ALB in liver; lane 6: CK19 in liver; lane 7: empty control; lane 8: CK19 in undifferentiated HOCs; lane 9: ALB in undifferentiated HOCs; lane 10: empty control; lane 11: CK19 in differentiated HOCs; lane 12: ALB in differentiated HOCs; lane 13: empty control.
Table 2. Biochemical indicators for liver function.

\begin{tabular}{lcc}
\hline & Control $(n=8)$ & HOC transplantation $(n=14)$ \\
\hline ALT $(\mathrm{U} / \mathrm{L})$ & $968 \pm 203$ & $127 \pm 19^{*}$ \\
DBil $(\mu \mathrm{M} / \mathrm{L})$ & $80.0 \pm 21.8$ & $22.1 \pm 7.9^{*}$ \\
ALB $(\mathrm{g} / \mathrm{L})$ & $8.2 \pm 1.6$ & $14.8 \pm 2.4^{*}$ \\
GGT $(\mathrm{U} / \mathrm{L})$ & $355 \pm 165$ & $65.9 \pm 14.4^{*}$ \\
ALP $(\mathrm{U} / \mathrm{L})$ & $680 \pm 190$ & $256 \pm 21^{*}$ \\
ChE $(\mathrm{U} / \mathrm{L})$ & $481 \pm 186$ & $1838 \pm 258^{*}$ \\
\hline
\end{tabular}

Data are reported as means $\pm S D$. The indicators were measured 4 weeks after transplantation. ALT: alanine aminotransferase; Dbil: direct bilirubin; ALB: albumin; GGT: $\gamma$-glutamyltransferase; ALP: alkaline phosphate; ChE: cholinesterase. The average ALP value in recipient rats was $138 \pm 17(\mathrm{U} / \mathrm{L}) 1$ day prior to transplantation. ${ }^{*} \mathrm{P}<0.05$ vs control (Student $t$-test).

procedure was modified in the present study, whereby only the left lateral lobe was excised (one-half to one-third $\mathrm{PH}$ ). By using this optimized 2-AAF/PH protocol, the survival rate of the animals was greatly increased to $60 \%$ on the 10th day post-operation. It should be noted that no significant difference was observed in the number and properties of isolated HOCs between this modified method and the conventional 2-AAF combined with two-thirds $\mathrm{PH}$ $(23,24)$. These results suggest that $2-A A F$ in combination with one-half to one-third $\mathrm{PH}$ may serve as a novel and efficient approach for stimulating HOC proliferation.

Consistent with previous reports (9), the HOCs derived from the liver of Lewis rats after 2-AAF/PH treatment exhibited a typical oval cell morphology, with a diameter of 7-19 $\mu \mathrm{M}$, average size of $18.3 \pm 11.7 \mu \mathrm{m}^{2}$, high nucleus-tocytoplasm ratio, and enriched heterochromatin in the nucleus. It has been previously demonstrated that HOCs express c-kit, CK19, albumin, AFP, Thy-1 (CD90), and GGT $(25,26)$. In agreement with these findings, the isolated HOCs expressed markers of both the biliary epithelium (CK19) and hepatocyte lineages (ALB), and were positive for c-kit staining. In addition, these cells were positive for CD90 but negative for CD34, indicating that these cells were liver-derived hepatic progenitors.

After LIF withdrawal, a majority of the HOCs differentiated into long spindle-like bile duct epithelial cells, and only approximately one quarter of the differentiated HOCs were identified as hepatocytes. As ALB and CK19 were the indicators for hepatocyte and biliary epithelium, respectively, we quantitatively analyzed the mRNA expression of ALB and CK19 for the first time in undifferentiated and differentiated HOCs. No significant difference was detected in the expression of ALB before or after HOC differentiation $(P=0.076)$, while the mRNA level of CK19 was significantly enhanced after differentiation $(P=0.004)$, which could be due to the increased number of HOC-derived bile duct epithelial cells.

We investigated the potential capability of $\mathrm{HOC}$ transplantation for liver regeneration or repair. Our results 

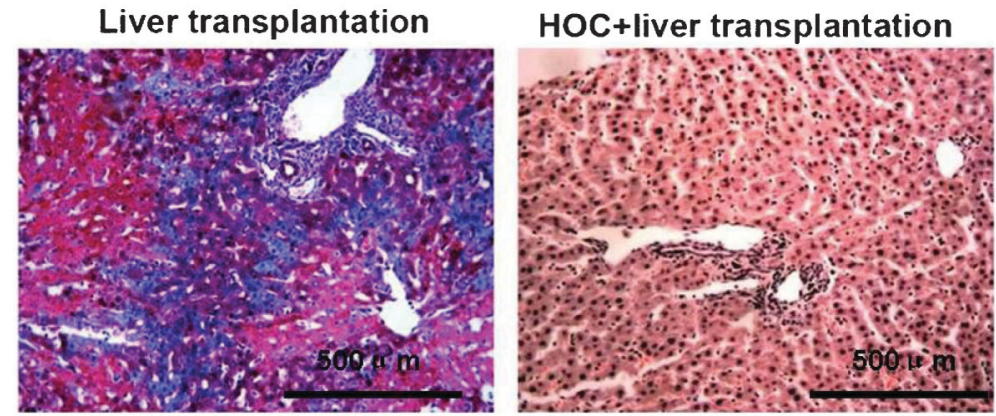

Figure 6. Histological examination of liver allograft rejection. Sections obtained from experimental groups were stained with hematoxylin \& eosin. demonstrated that $\mathrm{HOC}$ transplantation greatly prolonged the MST for recipients compared with the control $(P=0.003)$. Moreover, 4 weeks after transplantation, the levels of liver injury biomarkers, including ALT, DBil, GGT, and ALP, were significantly higher in rats of the control group than in the recipients of $\mathrm{HOC}$ transplantation $(P=0.002 ; P=0.014 ; P=0.007 ; P=0.025)$. These results suggested impaired liver function in the controls, which was improved by $\mathrm{HOC}$ transplantation. $\mathrm{HOC}$ transplantation also improved liver synthesis function, because ChE and ALB levels decreased 4 weeks after surgery compared to controls. It is possible that HOCs may proliferate and differentiate in the transplanted liver, contributing to improved liver synthesis function.

\section{References}

1. Chung H, Kim KH, Kim JG, Lee SY, Yoon YH. Retinal complications in patients with solid organ or bone marrow transplantations. Transplantation 2007; 83: 694-699, doi: 10.1097/01.tp.0000259386.59375.8a.

2. Patel H, Vogl DT, Aqui N, Shaked A, OlthoffK, Markmann J, etal. Posttransplant lymphoproliferative disorder in adult liver transplant recipients: a report of seventeen cases. Leuk Lymphoma 2007; 48: 885-891, doi: 10.1080/10428190701223275.

3. Tamsel S, Demirpolat G, Killi R, Aydin U, Kilic M, Zeytunlu $\mathrm{M}$, et al. Vascular complications after liver transplantation: evaluation with Doppler US. Abdom Imaging 2007; 32: 339347, doi: 10.1007/s00261-006-9041-z.

4. Tosh D, Strain A. Liver stem cells - prospects for clinical use. J Hepatol 2005; 42 (Suppl): S75-S84, doi: 10.1016/ j.jhep.2004.12.009.

5. Faris RA, Konkin T, Halpert G. Liver stem cells: a potential source of hepatocytes for the treatment of human liver disease. Artif Organs 2001; 25: 513-521, doi: 10.1046/ j.1525-1594.2001.025007513.x.

6. Fausto N, Campbell JS. The role of hepatocytes and oval cells in liver regeneration and repopulation. Mech Dev 2003; 120: 117-130, doi: 10.1016/S0925-4773(02)00338-6.

7. Paku S, Schnur J, Nagy P, Thorgeirsson SS. Origin and structural evolution of the early proliferating oval cells in rat liver. Am J Pathol 2001; 158: 1313-1323, doi: 10.1016/ S0002-9440(10)64082-5.

8. Lemire JM, Shiojiri N, Fausto N. Oval cell proliferation and the origin of small hepatocytes in liver injury induced by
Administration of $\mathrm{HOCs}$ to rats also receiving liver transplantation greatly reduced acute allograft rejection compared to control liver transplant rats 3 weeks following transplantation. These results indicate that HOC may provide a novel option for therapeutic liver regeneration after orthotopic liver transplantation.

In summary, our study found that HOCs activated in a modified 2-AAF/PH model proliferate and differentiate into hepatocytes and bile duct epithelial cells with a preferential of biliary epithelium differentiation under specific conditions. The results also raise the possibility that HOC-based cell therapy can be combined with orthotopic liver transplantation to stimulate liver regeneration after surgery.

D-galactosamine. Am J Pathol 1991; 139: 535-552.

9. Wang X, Foster M, Al-Dhalimy M, Lagasse E, Finegold M, Grompe M. The origin and liver repopulating capacity of murine oval cells. Proc Natl Acad Sci U S A 2003; 100 (Suppl 1): 11881-11888, doi: 10.1073/pnas.1734199100.

10. Oh SH, Hatch HM, Petersen BE. Hepatic oval 'stem' cell in liver regeneration. Semin Cell Dev Biol 2002; 13: 405-409, doi: $10.1016 / S 1084952102001271$.

11. Crosby HA, Kelly DA, Strain AJ. Human hepatic stem-like cells isolated using c-kit or CD34 can differentiate into biliary epithelium. Gastroenterology 2001; 120: 534-544, doi: 10.1053/gast.2001.21175.

12. Coleman WB, McCullough KD, Esch GL, Faris RA, Hixson DC, Smith GJ, et al. Evaluation of the differentiation potential of WB-F344 rat liver epithelial stem-like cells in vivo. Differentiation to hepatocytes after transplantation into dipeptidylpeptidase-IV-deficient rat liver. Am J Pathol 1997; 151: 353-359.

13. Paku S, Nagy P, Kopper L, Thorgeirsson SS. 2-acetylaminofluorene dose-dependent differentiation of rat oval cells into hepatocytes: confocal and electron microscopic studies. Hepatology 2004; 39: 1353-1361, doi: 10.1002/ hep.20178.

14. Evarts RP, Nagy P, Marsden E, Thorgeirsson SS. A precursor-product relationship exists between oval cells and hepatocytes in rat liver. Carcinogenesis 1987; 8: 17371740, doi: 10.1093/carcin/8.11.1737.

15. Knight B, Matthews VB, Akhurst B, Croager EJ, Klinken E, 
Abraham LJ, et al. Liver inflammation and cytokine production, but not acute phase protein synthesis, accompany the adult liver progenitor (oval) cell response to chronic liver injury. Immunol Cell Biol 2005; 83: 364-374, doi: 10.1111/j.1440-1711.2005.01346.x.

16. Chiu CC, Huang GT, Chou SH, Chien CT, Chiou LL, Chang $\mathrm{MH}$, et al. Characterization of cytokeratin 19-positive hepatocyte foci in the regenerating rat liver after 2-AAF/ CCl4 injury. Histochem Cell Biol 2007; 128: 217-226, doi: 10.1007/s00418-007-0309-3.

17. Factor VM, Radaeva SA, Thorgeirsson SS. Origin and fate of oval cells in dipin-induced hepatocarcinogenesis in the mouse. Am J Pathol 1994; 145: 409-422.

18. Best DH, Coleman WB. Treatment with 2-AAF blocks the small hepatocyte-like progenitor cell response in retrorsineexposed rats. $J$ Hepatol 2007; 46: 1055-1063, doi: 10.1016/ j.jhep.2007.01.040.

19. Yang Y, Fukui K, Koike T, Zheng X. Induction of autophagy in neurite degeneration of mouse superior cervical ganglion neurons. Eur J Neurosci 2007; 26: 2979-2988, doi: 10.1111/ j.1460-9568.2007.05914.x.

20. Li N, Cai CJ, Wu YR, Lu MQ. A technique of recipient portal venoplasty and cuff insertion for portal revascularization in orthotopic rat liver transplantation. J Surg Res 2012; 176:
317-320, doi: 10.1016/j.jss.2011.09.026

21. Li J, Hou Y, Liu J, Liu B, Li L. A better way to do small-forsize liver transplantation in rats. Front Med 2011; 5: 106110, doi: 10.1007/s11684-011-0113-2.

22. Solez K. History of the Banff classification of allograft pathology as it approaches its 20th year. Curr Opin Organ Transplant 2010; 15: 49-51, doi: 10.1097/MOT.0b013e328334fedb.

23. Shiota G, Kunisada T, Oyama K, Udagawa A, Nomi T, Tanaka K, et al. In vivo transfer of hepatocyte growth factor gene accelerates proliferation of hepatic oval cells in a 2acetylaminofluorene/partial hepatectomy model in rats. FEBS Lett 2000; 470: 325-330, doi: 10.1016/S00145793(00)01337-5.

24. Zhang W, Chen XP, Zhang WG, Zhang F, Xiang S, Dong HH, et al. Hepatic non-parenchymal cells and extracellular matrix participate in oval cell-mediated liver regeneration. World $\mathrm{J}$ Gastroenterol 2009; 15: 552-560, doi: 10.3748/wjg.15.552.

25. Grompe M. The role of bone marrow stem cells in liver regeneration. Semin Liver Dis 2003; 23: 363-372, doi: 10.1055/s-2004-815560.

26. Petersen BE, Goff JP, Greenberger JS, Michalopoulos GK. Hepatic oval cells express the hematopoietic stem cell marker Thy-1 in the rat. Hepatology 1998; 27: 433-445, doi: 10.1002/hep.510270218. 